\title{
Estimating 24 Hour Sodium Urine from Spot Urine: A Correlation Model Among Aged 25-64 in Indonesia
}

\author{
Ekowati Rahajeng ${ }^{1}$, Nunik Kusumawardani ${ }^{1}$, Rika Rachmawati ${ }^{1}$ \& Fitrah Ernawati $^{2}$ \\ ${ }^{1}$ Centre for Public Health Research and Development, National Institute of Health Research and Development \\ Ministry of Health Republic of Indonesia \\ ${ }^{2}$ Biomedical and Basic Health Technology Research and Development Centre, National Institute of Health \\ Research and Development Ministry of Health Republic of Indonesia \\ Correspondence: Nunik Kusumawardani, Centre for Public Health Research and Development National Institute \\ of Health Research and Development, Ministry of Health Republic of Indonesia, Jl. Percetakan Negara 29 Jakarta, \\ Indonesia.
}

Received: February 26, 2021 Accepted: April 15, 2021 Online Published: May 8, 2021

doi:10.5539/gjhs.v13n6p49 URL: https://doi.org/10.5539/gjhs.v13n6p49

\begin{abstract}
Introduction: Excess salt intake is known to raise blood pressure and in turn increase the risk of cardiovascular disease. Data and information on sodium consumption in Indonesia is limited, while examination method using 24-hour urine examination is a complex method to apply in population based survey. Objective: to estimate value of spot urinary excretion against 24-hour urine values and correction factors.

Method: Validation was carried out through 24-hour urine and spot urine examination, in 423 individual aged 25-65 years in the Kebun Kelapa Village, Bogor City, Indonesia in 2017. Urine sodium examination method was carried out by laboratory examination inductively coupled plasma optical emission spectrometry (ICP-OES). Accuracy and precision are valued by paired test correlations and mean differences. The coefficient of determination (R Square) is calculated for sodium intake estimation and its correction factors.

Results: The sodium value of morning spot urine has better precision and stronger correlation with the sodium value of 24-hour urine than the sodium value of afternoon spot urine. The difference in average morning sodium urine with 24-hour urine sodium according to age and sex was not significantly different ( $\mathrm{t}$ test 0.30 and $\mathrm{p}=0.77$ ), had a positive and moderate correlation (paired $r=0.50$ and $p=0.00$ ). The average difference between the estimated evening urine sodium spot was different $(\mathrm{t}$ test $=7.32$ and $\mathrm{p}=0.00)$, and the correlation was very weak $(\mathrm{r}$ $=0.25 ; \mathrm{p}=0.00)$.
\end{abstract}

Conclusion: the urine content / sodium spot level was accurate to estimate urine sodium value / content 24 hours.

Keywords: 24 hour sodium urine, spot urine

\section{Introduction}

Excess salt intake is known to cause raised blood pressure and hypertension that in turn directly or indirectly cause heart problems and diseases (including coronary heart disease, CHD / CHD; and vascular heart, CVD) (Campbell et al., 2012; Cappuccio, Capewell, Lincoln, \& McPherson, 2011; Hawkes \& Webster, 2012; Feng, He, Li, \& MacGregor, 2013). Heart disease and stroke are the main causes of death in Indonesia. The prevalence of hypertension of Indonesian people aged older than 18 years is quite high, namely 25.8\% (National Institute for Health Research \& Development [NIHRD], 2013). The Indonesian Food Consumption Survey data in 2014 shows that the average of sodium intake of the Indonesian population was $2764 \mathrm{mg} /$ day, 52.7 percent of the population consume more than $2000 \mathrm{mg}$ /day (Prihatini, Permaesih, \& Julianti, 2017). WHO suggests the recommended amount of consumption of no more than 5 grams of salt per day which correspond to $2000 \mathrm{mg}$ of sodium. A nationwide efforts to limit populations salt consumption can prevent the occurrence of diseases and deaths associated with excessive sodium consumption. This has been proven in various countries including China, England (UK), Europe, Japan, North America (Okuda et al., 2014). This effort is expected to be followed by other countries including Indonesia. Indonesia`s national sodium data is needed, both as a program's baseline data to limit consumption of sugar, salt, fat and to monitor the effectiveness of the intervention program implemented.

The Indonesian Ministry of Health seeks to protect the community from NCD (NonCommunicable Diseases) 
through the recommendation of reducing the consumption of salt and control people's habits (behavior, health knowledge due to excessive salt consumption). The Ministry of Health's efforts to protect the public from the risk of getting the disease have not reached expectations because information on consumption behavior related to sodium and the magnitude of the problem of sodium intake in Indonesia are still very limited. The most accurate value of sodium intake is through 24-hour urine sodium excretion, but this examination is expensive and difficult to apply to surveys in the community. Examination of spot urine can be used to estimate the value of urinary sodium excretion 24 hours, but requires validation and correction factors (Ji et al., 2012).

This study validates the examination of current / spot sodium urine excretion (morning and evening) as an estimated 24-hour urine sodium value. In this paper, the accuracy and precision of spotted urine examination (morning or evening) will be conveyed for estimating 24-hour urine sodium levels, and conversion rates and correction factors (Estimation Formulas) sodium urine levels results of spot urine excretion in estimating 24-hour urine value.

\section{Method}

\subsection{Study Design}

This research is a validation study of examination methods and behavioral surveys conducted cross-sectionally. Validation was carried out between the results of sodium excretion in morning spot urines and afternoon spots with laboratory examination (ICP), compared with 24-hour urine sodium secretion values as gold standard. Estimated 24-hour sodium excretion rate is calculated based on the PAHO formula, namely: the value of spot urine examination results divided by the value / creatinine spot examination results multiplied by 24-hour urine examination value. The research was conducted in Bogor City, West Java. Data collection was carried out from September to December 2017.

\subsection{Population and Sample}

The population of this study were residents aged 25 years and over who lived in Bogor City, West Java. The sample was determined to follow the validation protocol for 24-hour urine and urine examination methods.

The number of samples was calculated based on the number of changes in the minimum urine excretion and the standard deviation value obtained by the minimum number of samples per age group and gender were 120 people with rounding for non-response estimation, it took 150 people in each age group and 2 sex groups ( $2 \times 2$ groups) so the total sample needed were 150 people $x 4$ groups $=600$ people. Age groups include: 1 ). $25-49 ; 2) 50+$ years. This sample size calculation reffered to the 24-hour urine intake survey guidelines from WHO PAHO page 12 (WHO/PAHO, 2010).

The sample (participants) were selected purposively according to the inclusion and exclusion criteria and the necessary number of participants in each sub-group (age, sex). Inclusion criteria in accordance with the overall research protocol included: participants were settlers who live for more than one week or not commuters, aged 25 years and above, not being disturbed or suffering from diseases related to urinary / sodium excretion (during data collection), not taking medication, supplements and or herbs related to urinary / sodium excretion (the list will be included) in the past month, can be invited to collaborate (cooperative). Participants who were pregnant or breastfeeding, have special needs (physical and physical disabilities) and have severe illness were excluded.

Data collection was carried out by a data collection team consisting of 6 Nutrition Scholars. Before conducting data collection, enumerators and supervisors received special training. The teacher was a core research team from the Health Research and Development Agency that has appropriate competencies.

The method of urine collection was done for 24 hours, which is te started from waking up until the next day. Urine came out shortly after waking up was not accommodated. Urine that came out next, for example at 5 am was accommodated until 5 am the next day. Every urine that came out must be accommodated in the container provided and recorded in the form provided. Collection of morning urine was when urinated around 8 am to 9 am. Collection of spotted urine during the afternoon was when urinated around $2 \mathrm{pm}$ until $3 \mathrm{pm}$ During the collection of urine, the urine collection container must always be closed and placed in a cool place (the room was far from the heat source) and protected from direct sunlight. Urine that came out along with defecating must still be accommodated (do urinate first).

Calculation of estimated 24-hour urine excretion sodium levels was calculated based on the PAHO formula (WHO/PAHO, 2010) :

Estimated 24-hour urine sodium excretion $(\mathrm{mEq})=\frac{\text { sodium spot urine }\left(\frac{m E q}{L}\right)}{\text { creatinine } \operatorname{spot}\left(\frac{\mathrm{mg}}{L}\right)} \times 24$ hour creatinine $(\mathrm{mg})$ 
Estimated sodium value of 24-hour urine excretion was calculated in 4 groups / sub-samples including gender (male, female) and three age groups $(25-40 ; 41-55 ; 55+$ years). 24-hour urine sodium examination results with ICP was used as the gold standard.

The precision of the spot urine examination value in estimating the sodium value of 24 hours urine was calculated based on the magnitude of the difference in mean value and $\alpha$ value ( $p$ value) from the paired test difference in mean value and standard deviation. The greater the p-value, shows the difference in the value of the examination results were not significantly different (the same) that indicates the magnitude of the difference between 24-hour urine and spot urine. Precision calculations were performed according to age group and gender.

Results accuracy of the examination, was assessed based on the correlation coefficient based on the $r$ value of the paired test. The coefficient of determination (R Square) from the results of linear regression analysis with the fit model, was calculated to determine the ability of individual predictions / estimates. Correlation coefficient and Square R from conventional spot urine examination results and examination results with a digital device in estimating the results of 24-hour urine examination were used as a basis for assessing the accuracy of examination results on each type of examination instrument. Correlation calculations were carried out in each sub-sample age group and gender. The strength of the correlation was considered strong if $r>0.7$, moderate if $0.5<\mathrm{r}<0.7$, weak correlation if $0.3<\mathrm{r}<0.5$ and very weak or no correlation if $\mathrm{r}<0.3$. Examination of sodium spot urine was considered to be more accurate if the coefficient of determination ( $\mathrm{R}$ squared) obtained from the estimation calculation was directing toward positif, as high R-squared may not always indicates good model.

\section{Results}

Data collection was carried out for 12 days, including briefing of ways to collect urine. Laboratory tests, especially creatinine, were carried out directly on the day of urine delivery. Urine examination (ICP, digital test with Spotchem, and digital test Easylyte) which cannot be directly implemented on the day of urine delivery due to limited examination facilities, was immediately stored in the refrigerator with a temperature of minus 80 degrees $\mathrm{C}$. The number of participants who can collect their data in full (24-hour urine, morning spot urine, afternoon spot urine) were 625 people. Table 1 shows that there were more female than male participants. Respondents age were ranging from 25 years to 65 years with average of 48.34 years, and more than $50 \%$ of respondents were $41-55$ years.

Table 1. Respondents Characteristics

\begin{tabular}{llll}
\hline Characteristics & $\mathrm{n}$ & $\%$ & Mean \\
\hline Sex & 297 & 47.5 & - \\
Males & 328 & 52.5 & - \\
Females & & & \\
Age (years) & 149 & 23.9 & 36.03 \\
$25-40$ & 476 & 76.1 & 52.19 \\
$41-65$ & 625 & 100.0 & 48.34 \\
\hline Total & & & \\
\hline
\end{tabular}

Coronary Heart Disease (CHD), diabetes mellitus (DM), and Stroke are Non-Communicable Diseases (NCD) that can affect the kidneys in producing urine, related to the drugs consumed and metabolic disorders that occur in the disease. To get more specific analysis results, participants who have the disease were excluded from the next analysis, and need to be analyzed specifically.

The presence or absence of CHD experienced by participants was determined by a coronary heart specialist based on the results of ECG examination and clinical interview. The presence or absence of a Stroke disorder was based on the results of a neurological examination by a neurologist. While the presence or absence of DM disease was determined based on the results of clinical interviews and examination of blood glucose (fasting and 2 hours of glucose loading). The number of participants who did not have NCD and further analysis was 423 people.

\subsection{Estimation Value, Mean Different and Correlation}

The estimated sodium value of 24 hours is calculated by the PAHO formula, namely; Y (urine sodium estimation 24 hours $)=\{$ sodium spot $(\mathrm{X}) /($ creatinine spot urine value) $\mathrm{mg}$ or $\mathrm{g} / \mu \mathrm{g}$ creatinine $\mathrm{x}$ (expected 24 -h creatinine 
excretion value 24 hours) $\}$. Participant exclusion was conducted according to the results of the NCD risk factor cohort study, which was issued in November 2017. The results of data analysis in participants who did not suffered certain non communicable diseases $(n=423)$.

Table 2. Mean Difference and Correlation of 24hrs Sodium Urine in Estimation Based on Morning Sodium Spot Urine ( $\mathrm{mg} /$ day)

\begin{tabular}{|c|c|c|c|c|c|c|c|c|c|c|}
\hline \multirow{2}{*}{ Characteristics } & \multirow{2}{*}{$\mathrm{n}$} & \multicolumn{2}{|c|}{24 hrs sodium urine (ICP lab) } & \multicolumn{2}{|c|}{ Morning sodium spot urine ICP } & \multicolumn{3}{|c|}{ Mean difference } & \multicolumn{2}{|c|}{ Correlation } \\
\hline & & mean & SD & mean & $\mathrm{SD}$ & difference & $t$ Test & $p$ & $r$ & $p$ \\
\hline \multicolumn{11}{|l|}{ Sex } \\
\hline Males & 223 & 3011.5 & 1373.7 & 3078.5 & 2265.9 & 67.0 & 0.51 & 0.61 & 0.51 & 0.00 \\
\hline Females & 200 & 3051.8 & 1295.5 & 2916.7 & 2288.2 & -135.1 & 0.97 & 0.34 & 0.49 & 0.00 \\
\hline \multicolumn{11}{|l|}{ Age (years) } \\
\hline $25-40$ & 135 & 3251.2 & 1320.6 & 3336.2 & 2472.4 & 84.9 & 0.47 & 0.64 & 0.52 & 0.00 \\
\hline $41-65$ & 288 & 2927.1 & 1332.7 & 2845.3 & 2163.4 & 81.7 & 0.73 & 0.47 & 0.49 & 0.00 \\
\hline Total & 423 & 3030.5 & 1335.9 & 3002.0 & 2275.2 & 28.5 & 0.30 & 0.77 & 0.50 & 0.00 \\
\hline
\end{tabular}

Note. Total subject: 423 people and exclude subject with stroke, coronary heart diseases and diabetes.

Table 2 shows that there is no significant difference between the mean sodium urine from the estimation results based on the morning spot urine and ICP examination with 24-hour urine average ( $t$ test $=0.30$ and $p=0.77$ ). The average difference in estimated sodium urine with 24 hours of urine sodium (examination) according to sex was found to be insignificant, with $\mathrm{p}=0.61$ in men and $\mathrm{p}=0.34$ in women.

The difference in mean sodium urine estimation with morning spot, based on ICP examination according to age group was also found to be insignificant $(\mathrm{p}>0.5)$.

Paired test of individual correlation between sodium urine estimation at morning spot based on ICP examination with 24 hours (examination) urine sodium was found to be significantly positive with moderate correlation ( $\mathrm{r}=$ $0.50 \mathrm{p}=0.00)$. Correlation according to sex was also found to be moderate, both in men $(r=0.51 ; p=0.00)$ and women $(r=0.49 ; p=0.00)$. Likewise the correlation according to age group. In the age group of $25-40$ years, a moderate correlation was found $(r=0.52 ; \mathrm{p}=0.00)$, in the $41-65$ year age group it was weak correlation $(\mathrm{r}=0.49$; $\mathrm{p}=0.00)$.

Table 3. Mean Difference and Correlation of 24hrs Sodium Urine in Estimation Based on Evening Sodium Spot Urine ( $\mathrm{mg} /$ day)

\begin{tabular}{|c|c|c|c|c|c|c|c|c|c|c|}
\hline \multirow[t]{2}{*}{ Characteristics } & \multirow[t]{2}{*}{$\mathrm{n}$} & \multicolumn{2}{|c|}{$\begin{array}{l}24 \text { hrs sodium urine } \\
\text { (ICP lab) }\end{array}$} & \multicolumn{2}{|c|}{$\begin{array}{l}\text { Evening sodium } \\
\text { spot urine ICP }\end{array}$} & \multicolumn{3}{|c|}{ Mean difference } & \multicolumn{2}{|c|}{ Correlation } \\
\hline & & mean & SD & mean & SD & difference & $t$ Test & $p$ & $r$ & $p$ \\
\hline \multicolumn{11}{|l|}{ Sex } \\
\hline Males & 223 & 3011.5 & 1373.7 & 6372.8 & 8360.0 & 3361.3 & 6.15 & 0.00 & 0.24 & 0.00 \\
\hline Females & 200 & 3051.8 & 1295.6 & 4947.7 & 6850.7 & 1895.9 & 4.05 & 0.00 & 0.27 & 0.00 \\
\hline \multicolumn{11}{|l|}{ Age (years) } \\
\hline $25-40$ & 135 & 3251.2 & 1320.6 & 5637.0 & 5749.9 & 2385.8 & 5.06 & 0.00 & 0.31 & 0.00 \\
\hline $41-65$ & 288 & 2927.1 & 1332.1 & 5728.1 & 8487.6 & 2801.1 & 5.74 & 0.00 & 0.23 & 0.00 \\
\hline Total & 423 & 3030.5 & 1335.9 & 5699.0 & 7713.2 & 2668.5 & 7.32 & 0.00 & 0.25 & 0.00 \\
\hline
\end{tabular}

The average difference between the estimated afternoon sodium spot urine based on ICP examination with 24-hour urine (examination) was found to be different in terms ( $t$ test $=7.32$ and $p=0.00)$. The positive correlation was found to be significant with $\mathrm{r}=0.25(\mathrm{p}=0.00)$. The average 24-hour sodium estimation with an afternoon sodium 
spot urine based on ICP examination was found to be higher $(5699.0 \mathrm{mg})$ than 24-hour urine sodium examination results $(3030.5 \mathrm{mg})$. The difference in standard deviation was found to be very large ( $\mathrm{SD}=7713.2 \mathrm{mg}$ vs. 1353.9 $\mathrm{mg})$.

The mean difference according to gender and age group was also found to be always significant $(p=0)$. Both by sex and by age group, the average urine estimate of 24 hours based on sodium spot urine in the afternoon with ICP examination tends to be greater than the mean sodium urine 24 hours (examination), with a higher standard deviation.

The difference in mean urine estimation 24 hours based on sodium spot urine afternoon from the results of ICP examination with 24 hour urine (examination) according to age groups was also found to be significant. According to age group, the average estimated urine sodium 24 hours based on the afternoon spot urine with ICP examination tends to be higher than the mean urine24 hours (examination), as well as the standard deviation.

Paired test correlation between urine sodium estimated value based on spot urine afternoon ICP results with urine 24 hours (examination) was found to be significant, but with very weak strength $(\mathrm{r}=0.25 \mathrm{p}=0.00)$. Correlation according to gender was found to be very weak ( $r=0.24$ in men and $r=0.27$ in women). Whereas according to the age group also found positive association $(\mathrm{r}=0,24-0,38)$.

\subsection{Regression Analysis of Linear Model Fit}

Table 4 shows the results of multivariate linear regression analysis with a fit model, in order to determine the estimation of 24-hour urine sodium from the results of spot urine examination. Multivariate linear regression analysis was performed on data sets with exclusion of CHD, DM and stroke $(\mathrm{N}=423)$, with morning spot urine sodium test results.

Table 4. Linear Regression Model of Fit of 24 hour Sodium Urine Based on Morning Spot Urine ( $N=423$ )

\begin{tabular}{lllll}
\hline Variable & Standardized Coefficients $\beta$ & $\mathrm{t}$ & $\mathrm{p}$ & $\mathrm{R}$ Square ajusted \\
\hline ICP laboratory test & & & & \\
Sodium Urine (Na/K x K24 hours) & 0.47 & 11.18 & 0.00 & 0.290 \\
Age (years) & -0.10 & -2.49 & 0.01 & \\
Body Mass Index (BMI) & 0.16 & 3.95 & 0.00 & 0.274 \\
\hline Sodium Urine (mg/24hrs) & 0.45 & 10.60 & 0.00 & \\
Age (years) & -0.09 & -2.30 & 0.02 & \\
Body Mass Index (BMI) & 0.14 & 3.40 & 0.00 & \\
\hline
\end{tabular}

The variables included in the analysis were age, sex, and BMI. Based on the fit model multivariate linear regression analysis, the factors found to affect the estimated urine value of 24 hours of individual morning spot urine sodium values $(\mathrm{p}<0.05)$ were age and body mass index.

Through correction of sodium spot urine value with creatinine value (Sodium Spot urine (Na / KSpot x K24h), estimation of urine sodium 24 hours based on morning sodium spot urine from ICP examination has R Square 0.290 . The analysis results obtained $\beta$ Standardized Coefficients for Sodium $(\mathrm{Na} / \mathrm{KSpot}$ urine $\mathrm{x}$ K24 hours $)=0.47$, for Age $=-0.10$, and for BMI $=0.16$. Overview of linear regression lines and distribution of estimated values can be seen in Figure 1. The regression equation was $Y=0,47$ (Natrium/Kreatinin morning Urine Spot $x 24$ hours creatinine) $-0,10$ (age) $+0,16$ (BMI).

Without correction of creatinine value, a 24-hour urine sodium estimation based on sodium of morning spot urine from ICP examination has R Square 0.274. The analysis results obtained Standardized Coefficients $\beta$ for Sodium $=$ 0.45 , for Age $=-0.09$, and for $\mathrm{BMI}=0.14$. The regression equations were the following $Y=0,45$ (Natrium morning spot urine) $-0,09$ (age) $+0,14$ (BMI). The description of linear regression lines and the distribution of estimated values can be seen in Figure 2. It can be seen from Figure 1 and Figure 2 that it may need to run residual analysis for model correction. 


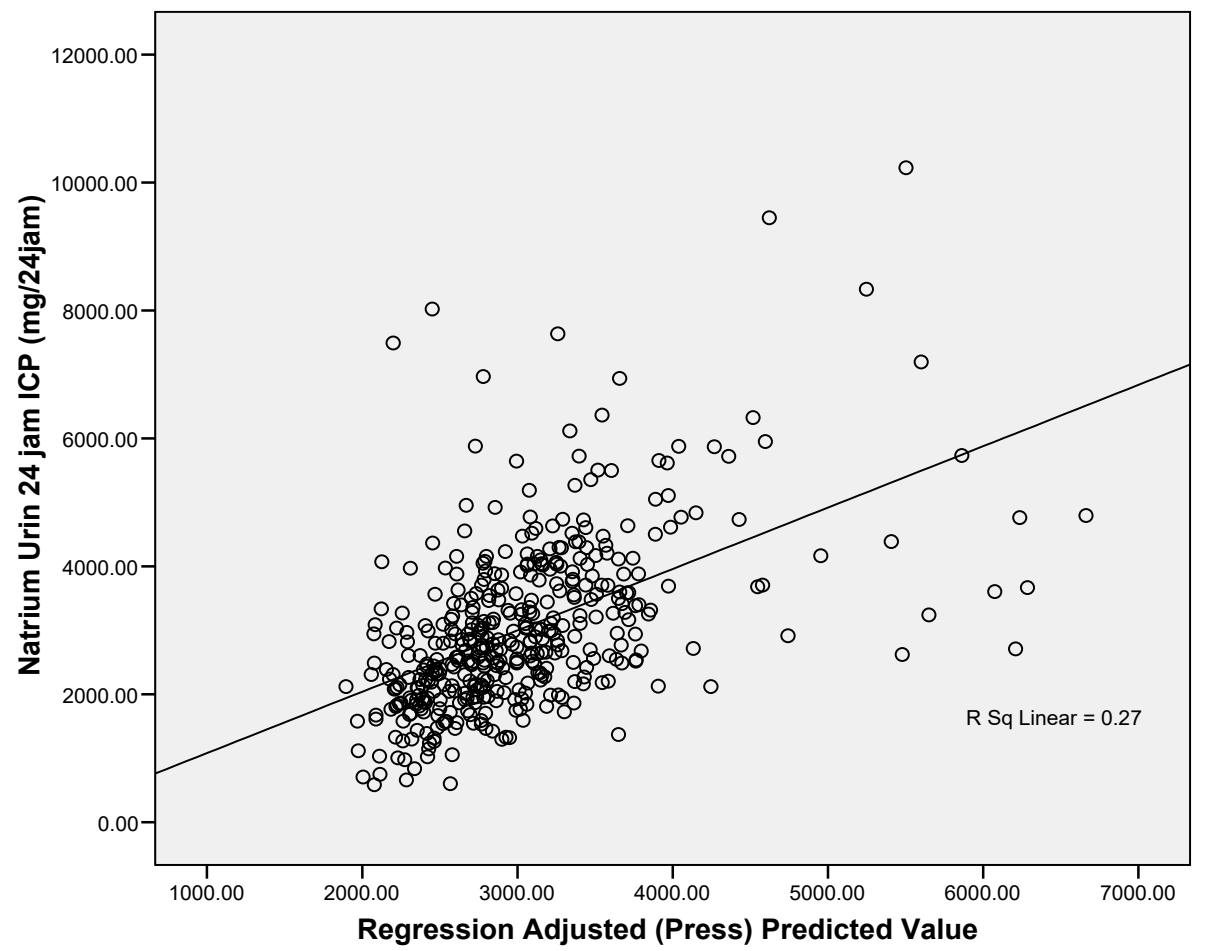

Figure 1. Linear Regression of Estimating 24 hours Sodium Urine Based on Morning Spot Urine Corrected by Creatinine Urine (Na/K US x K24hrs) Measured by ICP Lab ( $\mathrm{N}=423)$

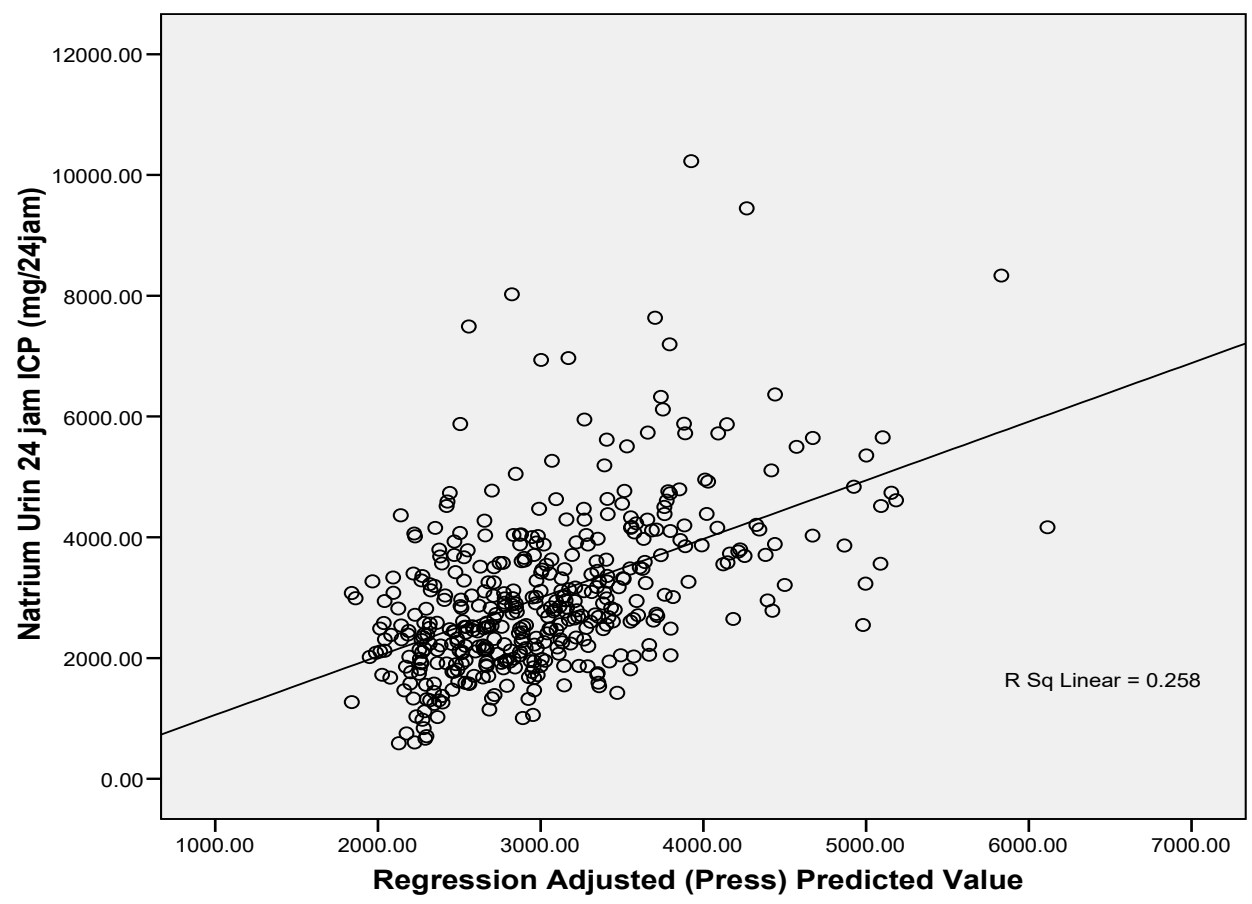

Figure 2. Linear Regression of Estimating 24 hours Sodium Urine Based on Morning Spot Urine by ICP Laboratory Test ( $\mathrm{N}=423)$ 
Table 5. Statistical of Residual Analysis of ICP 24 hours sodium urin ( $\mathrm{mg} / 24$ hours)

\begin{tabular}{llllll}
\hline & Minimum & Maximum & Mean & Std. Deviation & N \\
\hline Predicted Value & $1,895.9977$ & $6,062.0103$ & $2,979.3314$ & 664.02585 & 625 \\
Std. Predicted Value & -1.631 & 4.642 & 0.000 & 1.000 & 625 \\
Standard Error of Predicted Value & 48.762 & 234.341 & 90.441 & 27.555 & 625 \\
Adjusted Predicted Value & $1,900.5605$ & $6,139.6548$ & $2,979.6354$ & 664.40623 & 625 \\
Residual & $-2,754.36182$ & $10,330.99512$ & 0.00000 & $1,178.89520$ & 625 \\
Std. Residual & -2.331 & 8.742 & 0.000 & 0.998 & 625 \\
Stud. Residual & -2.352 & 8.758 & 0.000 & 1.001 & 625 \\
Deleted Residual & $-2,805.26758$ & $10,369.12891$ & -0.30399 & $1,186.92561$ & 625 \\
Stud. Deleted Residual & -2.361 & 9.348 & 0.002 & 1.013 & 625 \\
Mahal. Distance & 0.064 & 23.540 & 2.995 & 2.720 & 625 \\
Cook's Distance & 0.000 & 0.071 & 0.002 & 0.006 & 625 \\
Centered Leverage Value & 0.000 & 0.038 & 0.005 & 0.004 & 625 \\
\hline
\end{tabular}

a. Dependent Variable: Natrium Urine 24 hours ICP (mg/24 hours).

\section{Discussion}

This study indicates that spot urine examination is valid to be conducted for the 24 hours urine estimation of sodium intake measurement using the regression formula that include weight, height (BMI) and age in small city that most likely describe a spesific semi urban Indonesian population that geographically close to the capital city (approximately $53 \mathrm{~km}$ ). Similar concept with other studies from different countries, the formula simply valid for the agregated data not for individual diagnose of sodium intake (Xu et al., 2020). A spot urine measurement has been developed in many countries as an alternative for more feasible method to estimate the 24 hours sodium urine test for population.

Previous study in Japan, by Tanaka, shows regression formulas in the following: (1) PRCr (mg/day) $=-2.04-$ age +14.89 -weight $(\mathrm{kg})+16.14$ - height $(\mathrm{cm})-2244.45 ;(2)$ estimated $24 \mathrm{HUNaV}(\mathrm{mEq} /$ day $)=21.98-$ $\mathrm{XNa} 0.392$; (3) estimated $24 \mathrm{HUKV}(\mathrm{mEq} /$ day $)=7.59-\mathrm{XK} 0.431$; where $\mathrm{PRCr}=$ predicted value of $24 \mathrm{HUCr}$, $\mathrm{SUNa}=\mathrm{Na}$ concentration in the spot voiding urine, $\mathrm{SUK}=\mathrm{K}$ concentration in the spot voiding urine, $\mathrm{SUCr}=$ creatinine concentration in the spot voiding urine, $\mathrm{XNa}$ (or XK) = SUNa (or SUK)/SUCr - PRCr.(Tanaka et al., 2002) A study in South Korea, finds that sensitivity of formula in estimating the 24-hr-urine sodium was around $84.3 \%$, while the Tanaka formula was $87.6 \%$ (Charlton et al., 2020; Koo et al., 2014).

Sodium $(\mathrm{Na})$ is consumed from food either in the form of sodium chloride salt $(\mathrm{NaCl})$, flavor enhancer (sodium glutamate), or preservative (Sodium benzoate, $\sim$ bicarbonate, $\sim$ carbonate). There are two main sources of salt in the diet, namely salt added during cooking, or at the table (salt, MSG, soy sauce), processed food including preserved food (salted fish, corned beef) and processed food factory products (biscuits, crackers, etc.) (Brown, Tzoulaki, Candeias, \& Elliott, 2009). Salt consumption about 5000 years ago before the Chinese people found a way to preserve food with salt of about 0.25 grams equivalent to 500 grams of sodium (He \& MacGregor, 2009).

Role of food industry in individual salt intake is considered to be significant as it leads to salty food habituation. They use high salt content in the processed food to meet the consumer's preference. The food industry mostly shows resistancy in reducing salt content of processed food. In fact, experience in UK showed that lowering salt content in processed food did not cause sales reduction (He \& MacGregor, 2009). In Indonesia, sources of consumption of sodium foods come mainly from salt and processed foods (instant noodles, crackers), preserved foods (salted fish), seasonings (soy sauce) and flavor enhancers (monosodium/sodium glutamate, MSG). Salt is the largest contributor of sodium intake, accounted to $62.43 \%$ (Kementerian Kesehatan, 2014).

Sodium is presented in intra- and intercellular. Sodium along with potassium $(K)$ is an important element in maintaining cellular homeostasis, maintaining the balance of osmotic pressure and the distribution of body fluids so that nutrients, hormones, enzymes can come out and enter the cell. Normal level of sodium in blood plasma is between $136-146 \mathrm{mEq} \mathrm{Na} / \mathrm{L}$. To maintain this level, sodium intake is needed between $90-250 \mathrm{mEq} \mathrm{Na} /$ day. Sodium concentrations are excreted through urine as much as $80-18^{\circ}-0 \mathrm{mEq} \mathrm{NA} /$ day and can reflect sodium 
intake (Pohl HR, Wheeler JS, 2013). But sodium values in both urine and blood are influenced by individual sensitivity and habits. The value of urinary sodium can be increased due to excessive consumption of salt, consumption of diuretics, kidney inflammation, decreased function of the adrenal glands, consumption of drugs (corticosteroids, anti-inflammatory steroids, prostaglandins (peptic ulcer drugs, glaucoma), neurologic disorders, and certain antibiotics. The value of urinary sodium can be decreased due to hyper-aldosteronism, dehydration, diarrhea, heart / kidney failure, CKD, liver cirrhosis, and hypothyroidism (Sodium urine test_MedlinePlus Medical Encyclopedia, n.d.).

It is crucial for a country to identify the magnitude of sodium intake figure for nationwide population coverage, as a baseline to develop more effective health intervention which are based on the necessity for particular population characteristics such as gender and age group or geographycal areas. Applying the valid formula from sodium spot urine to estimate the 24 hours sodium urine within the nationwide population based survey will be less costly and more feasible in term of minimizing bias in urine collection method. Another study showed that urine spot sample might provide accurate estimates of the 24-h sodium excretion in children at a population level (Text, 2019). Several research questions need to be addressed in the future research include which sodium spot urine test device that provide more valid results in comparison to the ICP method; how is the sodium intake variation across different social economy, cultural, dietary habit, and geographical settings of population and whether same estimation formula can be applied.

\subsection{Limitations}

This study has limitations such as the analysis had not yet include the contribution of dietary habit towards the sodium intake; the results may valid only for the studied population settings (aged 25-64 years), and did not include different population settings or geographical areas (urban-rural, or accross provinces) for comparison; younger age group was not included (such as for adolescenst group).

\section{Conclusions}

There is a moderate, positive, linear relationship between sodium urine estimation at morning spot based on ICP examination with 24 hours (examination) urine sodium spot. The morning spot urine examination is valid to be conducted for the 24 hours urine estimation of sodium intake. Moderate correlations are observed, convenience, and low cost and hence can be considered in the use of the urine pot method to examine sodium excretion, given the least effort in monitoring of sodium intake.

\section{Competing Interests Statement}

The authors declare that there are no competing or potential conflicts of interest.

\section{References}

Brown, I. J., Tzoulaki, I., Candeias, V., \& Elliott, P. (2009). Salt intakes around the world: Implications for public health. International Journal of Epidemiology, 38(3), 791-813. https://doi.org/10.1093/ije/dyp139

Campbell, N. R. C., Dary, O., Cappuccio, F. P., Neufeld, L. M., Harding, K. B., \& Zimmermann, M. B. (2012). Need for coordinated programs to improve global health by optimizing salt and iodine intake. Revista Panamericana de Salud Publica/Pan American Journal of Public Health, 32(4), 281-286. https://doi.org/10.1590/S1020-49892012001000006

Cappuccio, F. P., Capewell, S., Lincoln, P., \& McPherson, K. (2011). Policy options to reduce population salt intake. BMJ (Online), 343(7820), 1-9. https://doi.org/10.1136/bmj.d4995

Charlton K., Ware L. J., Chidumwa G., Cockeran M., Schutte A. E., \& Naidoo N. K. P. (2020). Prediction of 24-hour sodium excretion from spot urine samples in South African adults : a comparison of four equations. Journal of Human Hypertension, 34, 24-33. https://doi.org/10.1038/s41371-019-0210-2

Hawkes, C., \& Webster, J. (2012). National Approaches to Monitoring Population Salt Intake: A Trade-Off between Accuracy and Practicality? PLOS ONE, 7(10), 1-8. https://doi.org/10.1371/journal.pone.0046727

He, F. J., \& MacGregor, G. A. (2009). A comprehensive review on salt and health and current experience of worldwide salt reduction programmes. Journal of Human Hypertension, 23(6), 363-384. https://doi.org/10.1038/jhh.2008.144

He, F. J., Li, J., \& MacGregor, G. A. (2013). Effect of longer term modest salt reduction on blood pressure: Cochrane systematic review and meta-analysis of randomised trials. BMJ (Online), 346(7903), 1-15. https://doi.org/10.1136/bmj.f1325

Ji, C., Sykes, L., Christina Paul, Dary, O., Legetic, B., Campbell, N. R. C., \& Cappuccio, F. P. (2012). Systematic 
review of studies comparing 24-hour and spot urine collections for estimating population salt intake. Revista Panamericana de Salud Publica/Pan American Journal of Public Health, 32(4), 307-315. https://doi.org/10.1590/S1020-49892012001000010

Kementerian Kesehatan. (2014). Buku Studi Diet Total: Survei Konsumsi Makanan Individu 2014.

Koo, H. S., Kim, Y. C., Ahn, S. Y., Oh, S. W., Kim, S., Chin, H. J., \& Park, J. H. (2014). Estimating 24-hour urine sodium level with spot urine sodium and creatinine. Journal of Korean Medical Science, 29, S97-S102. https://doi.org/10.3346/jkms.2014.29.S2.S97

National Institute for Health Research \& Development. (2013). Riset Kesehatan Dasar (National Health Survey). Ministry of Health Republic of Indonesia, (1), 1-303. https://doi.org/10.1007/s13398-014-0173-7.2

Okuda, N., Stamler, J., Brown, I. J., Ueshima, H., Miura, K., Okayama, A., ... \& Elliott, P. (2014). Individual efforts to reduce salt intake in China, Japan, UK, USA: What did people achieve? the INTERMAP population study. Journal of Hypertension, 32(12), 2385-2392. https://doi.org/10.1097/HJH.0000000000000341

Pohl, H. R., \& Wheeler J. S. (2013). Interrelations between Essential Metal Ions and Human Diseases, Metal Ions in Life Sciences 13. In Metal Ions in Life Sciences (Vol. 13). https://doi.org/10.1007/978-94-007-7500-8

Prihatini, S., Permaesih, D., \& Julianti, E. D. (2017). Asupan Natrium Penduduk Indonesia: Analisis Data Survei Konsumsi Makanan Individu (SKMI) 2014. Gizi Indonesia, 39(1), 15. https://doi.org/10.36457/gizindo.v39i1.205

Sodium urine test_MedlinePlus Medical Encyclopedia. (n.d.).

Tanaka, T., Okamura, T., Miura, K., Kadowaki, T., Ueshima, H., Nakagawa, H., \& Hashimoto, T. (2002). A simple method to estimate populational 24-h urinary sodium and potassium excretion using a casual urine specimen. Journal of Human Hypertension, 16(2), 97-103. https://doi.org/10.1038/sj.jhh.1001307

Text. (2019). Health and Medicine - Diet and Nutrition; New Findings Reported from M. Rios-Leyvraz and CoAuthors Describe Advances in Diet and Nutrition (Urine Spot Samples Can Be Used to Estimate 24- Hour Urinary Sodium Excretion in Children ). 2-4.

WHO/PAHO. (2010). Protocol for Population Level Sodium Determination In 24-Hour Urine Samples. Retrieved from https://www.paho.org/hq/dmdocuments/2013/24h-urine-Protocol-eng.pdf

Xu, J., Zhang, J., Liu, M., Bai, Y., Guo, X., Dong, J., ... \& Wu, J. (2020). Estimating 24-Hour Sodium Excretion from Spot Urine Samples in Chinese Adults: Can Spot Urine Substitute 24-Hour Urine Samples? Nutrients, 12(3), 798. https://doi.org/https://doi.org/10.3390/nu12030798

\section{Copyrights}

Copyright for this article is retained by the author(s), with first publication rights granted to the journal.

This is an open-access article distributed under the terms and conditions of the Creative Commons Attribution license (http://creativecommons.org/licenses/by/4.0/). 